SOME EFFECTS OF GLUCOSE SYRUP INGESTION UPON EXTENDED SUB-MAXIMAL SPORTS PERFORMANCE

\title{
Vaughan Thomas
}

Human Performance Laboratory, Physical Education Department, St.Mary's College Twickenham, Middlesex.

\section{INTRODUCTION.}

Down (1968) has summarized some evidence concerning carbohydrate metabolism during marathon running events and concludes that relatively large quantities of glucose are required to be consumed before, during and after ' marathon type' events. Saltin and Hermansen (1967) reinforce this view ...."practical experience indicates that a sugar intake during endurance events prevents hypoglycaemia. The present studies firmly emphasize the importance of carbohydrate as a fuel during heavy muscular exercise." Certainly performance, during what Thomas (1970) called "extended intermittent or constant aerobic" competition, and. "intermittent anaerobic" activity, is governed to an extent by the ability of the performers to avoid or delay hypoglycaemia, and to reduce the use of free fatty acids (FFA) as fuel. There is a fall in blood glucose during prolonged heavy work in fasting subjects Ahlborg(1967), Boge(1936), Christensen and Hansen (1939), Rodahl (1964). It has been demonstrated that FFA are the main fuel aerobically exercising muscles in the fasting state Reinheimer et al (1968), Havel et al (1963), Issekutz et al. (1963), Friedberg et al (1960), Carlson et al. (1963). but that when glucose is made continuously available during exercise glucose utilization is augmented-Sanders et al (1967) and fat mobilization is greatly reduced Havel et al (1963), Carlson et al (1963). Pre-exercise glucose ingestion increases exercise respiratory quotient, indicating a preference for carbohydrate as a fuel in the fed state Issekutz et al (1963). Since carbohydrates are most efficiently metabolized than fats, stamina sports competitors have the problem of ensuring a sufficient carbohydrate supply during prolonged exercise. One method has been proposed by Saltin and Hermansen (1967) of augmenting local muscular carbohydrate stores, but it is not certain if the amount of augmentation would have significant physiological effect during competition, and the method has a critical peak time benefit which would be unsuitable for sportsmen requiring to reproduce peak performances over several consecutive days or more.

A second method is to provide an oral carbohydrate supplement, about and during prolonged activity Issekutz et al (1963), Consolazio et al (1969) Whichelow et al (1968). This method has been the subject preference of many 
sportsmen and coaches for many years. The major problems of this method appear to be twofold. First is the problem of palatability. Glucose in powder form is difficult to ingest unless well mixed in a liquid and even then may be unpalatable and possibly nauseating. In tablet form it is somewhat more palatable, except when the mouth is dry either through dehydration or sympathetic repression of salivation. The ideal form would seem to be liquid, which could easily be made palatable by supplements, and would also permit exercise dehydration and desalinization to be offset.

The second problem is of establishing the optimal timing of glucose ingestion. The blood glucose curve varies greatly at different times after ingestion, especially when periods of strenuous exercise are undertaken. Though doubt exists concerning the precise relationships between the functions of various carbohydrate stores during exercise, and the permeability of cell membranes to glucose in the presence of differing levels of, for instance, insulin Reinheimer et al (1968), Pruett (1970), it seems reasonable to assume that high blood glucose levels will enhance performance Goldstein et al (1953), Beecham's Research Report (1966). In this case, glucose ingestion with the intention of producing high blood glucose levels during exercise must be carefully controlled from a temporal basis.

The present report, which amplifies a previous progress report Thomas (1970) deals with studies of the effects, during extended sub-maximal exercise, of oral administration of a proprietary glucose drink.

CALSAL (Beecham Products) Athletes' Glucose Drink containing 49\% $\mathrm{w} / \mathrm{v}$ Glucose Syrup and Mineral Salts contributing ( $\mathrm{mg} \%$ )

$\begin{array}{lllr}\text { Sodium (Na) } & 69.0 & \text { Chloride }(\mathrm{Cl}) & 71.8 \\ \text { Potassium (K) } & 17.6 & \text { Phosphate }\left(\mathrm{PO}_{4}\right) & 49.0 \\ \text { Calcium (Ca) } & 30.0 & \text { Glycerophosphate } & 121.1\end{array}$

One $\frac{1}{2}$ litre bottle provides 725 kilocalories

\section{Pilot Study.}

3 male physical education students (aged 18,19 and 31 years) were tested under 3 different conditions each, the test involving work of 60 minutes' duration, pedalling a cycle ergometer at $90 \mathrm{rpm}$ against a resistance of 150 watts. The 3 test conditions were: 
1. with no drink,

2. $150 \mathrm{ml}$ of glucose drink taken 15 minutes before exercise,

3. $150 \mathrm{ml}$ of glucose drink taken 45 minutes before exercise.

The subjects were tested between the hours of 1 and $6 \mathrm{p} . \mathrm{m}$. having fasted and refrained from drinking for at least 15 hours before the test. Factors investigated and mean changes recorded over the nine tests, were:

Factor

Blood Glucose

Urine Glucose

" Spec. Gravity

$" \mathrm{pH}$

" Chloride

Core Temp.

Mouth Dryness

Heart Rate

Vital Capacity

F.E.V. (1)

$\mathrm{O}_{2}$ Uptake

Blood Pressure Sys •

Dias.

Body Weight
Mean change

$51 \mathrm{mg} / 100 \mathrm{ml}$

$1.775 \mathrm{mg} / 100 \mathrm{ml}$

0.001

0.6

$50 \mathrm{mg} / 100 \mathrm{ml}$

$0.5^{\circ}$

0.6 of a point

$62.5 / \min$

0.03 litres

0.16 litres

$1.8 \%$

$3.5 \mathrm{~mm}$ mercury

$2.6 \mathrm{~mm}$ mercury

$10.9 \mathrm{~kg}$
Method of Measurement

Autoanalyzer .

Morley, Dawson and

Marks (1968).

Clinistix.

Ames \& Co. Information. 
The same 3 subjects were subjected to similar work tests to those described in the pilot study, with addition of a fourth test which involved taking the glucose drink and remaining at rest. Blood glucose was sampled every 15 minutes, $\mathrm{O}_{2}$ uptake every five minutes, heart rate continuously during exercise, and body weight immediately before and after exercise. The work was in these cases carried out on a treadmill with the subjects running at $10 \mathrm{kph}$ at a 1\% incline Astrand and Rhyming (1954). Only the blood glucose data showed significant changes, therefore the total glucose data for the 7 tests carried out on each of the three subjects were then treated by Analysis of Variance with the following results :

\begin{tabular}{l|c|c|c|c}
\hline \multicolumn{1}{c|}{ Source } & Sum of Squares & df & Var. Est. & 'F' Ratio \\
\hline S = Differences between & & & & \\
subjects & 2225.515 & 2 & 1112.758 & 5.69 \\
T = Time of sample during & & & & \\
work & 1425.45 & 2 & 712.73 & 3.64 \\
C = Experiment conditions & 36940.087 & 3 & 12313.362 & 62.95 \\
S v T interaction & 3191.64 & 4 & 797.91 & 4.08 \\
C v T interaction & 7408.421 & 6 & 1234.74 & 6.31 \\
C v S interaction & 7666.533 & 6 & 1277.76 & 6.53 \\
S v T v C interaction & 7321.965 & 12 & 610.16 & 3.12 \\
Residual & 7041.186 & 36 & 195.59 & \\
\hline Total & 73220.797 & 71 & & \\
\hline
\end{tabular}

The Series 1 data is presented in graphical form in Figure 1.

The significant ' $F$ ' value for the interaction between all experimental variables precludes a direct testing of the lower order and main effects. However, the treatment suggested by Satterthwaite (1946) demonstrates the acceptability of the very high ' $F$ ' for the experimental conditions variance as being significant, which view is supported by the graphical interpretation of the data. The greater part of this variance is attributable to the experimental condition of 'drink and 
no exercise', which is not entirely relevant to the problem of feeding a working subject, and was included merely as a control condition. If a secondary, twoway, analysis of variance is performed between the 'no drink' and the ' 45 minute pre-exercise drink' conditions, it can be seen that statistically the difference between them is not significant.

\begin{tabular}{l|c|c|c|c}
\hline \multicolumn{1}{c|}{ Source } & Sum of Squares & df & Var.Est. & 'F' Ratio \\
\hline $\begin{array}{l}\text { Difference between } \\
\text { experimental condition }\end{array}$ & 209.76 & 1 & 209.76 & 1.791 \\
Difference between time of & & & & \\
samples & 429.70 & 4 & 107.43 & \\
Interaction & 468.24 & 4 & 117.06 & \\
\hline Total & 1107.70 & 9 & & \\
\hline
\end{tabular}

A non parametric test Walsh (1969) applied to the data demonstrates the blood glucose boost at the beginning of exercise to be significant at the 0.031 level.

\section{Series 11.}

In this series of tests, six male physical education students (ages 26, $23,18,31,21,19,18)$ replicated the previous test on the treadmill. Each test was preceded by at least 15 hours of fasting, and each subject drank 1.5 litres of water during this time. Each subject was tested twice, taking $150 \mathrm{ml}$ of glucose drink either 45 or 30 minutes pre-exercise, followed at 30 minute intervals by three $50 \mathrm{ml}$ drinks. This procedure simulated competitive refeeding conditions. Blood glucose was assessed at 15 minute intervals from immediately before the first drink to 60 minutes post exercise. Heart rate was monitored continuously. 





The Series 11 glucose data were subjected to analysis of variance:

\begin{tabular}{l|r|r|c|c}
\hline \multicolumn{1}{c|}{ Source } & Sum of Squares & df & Var.Est. & 'F' Ratio \\
\hline C = difference between experi- & & & & \\
$\quad$ mental conditions & 9 & 1 & 9 & - \\
T = time of sample during & & & & \\
$\quad$ experiment & 59223.25 & 11 & 5383.93 & 9.02 \\
S = differences between subjects & 17793.25 & 5 & 3558.65 & 5.96 \\
C v T interaction & 3006.83 & 11 & 273.35 & - \\
C v S interaction & 18121.00 & 5 & 3624.20 & 6.07 \\
T v S interaction & 35220.25 & 55 & 640.37 & 1.07 \\
Residual & 32825.17 & 55 & 596.82 & \\
\hline Total & 116198.75 & 143 & & \\
\hline
\end{tabular}

These data are presented in graphical form in Figure 2, and the corresponding heart rate data in Figure 3. The significance of the differences in heart rates at each point were established with a Walsh test (op.cit.), those having probabilities 0.05 being designated ' + '.

\section{DISCUSSION}

The data can be regarded as proving some evidence concerning two major considerations; one, that ingestion of a proprietary glucose drink significantly affects physiological reactions to extended exercise, and two, that there are significant differences between ingestion timing routines. The experimental method has been biassed towards what can be termed 'long distance' sports performance, and the technique of pre-exercise fasting has been used both to standardize the experimental conditions and to simulate typical conditions of hypoglycaemia and dehydration experienced by 'marathon' sportsmen.

The Series 1 data illustrates the ever present bugbear of sports dietetics. The significance of higher order interactions indicates that individuals are so specific in their blood glucose reactions that main effects tend to become obscured. However, the extremely high ' $F$ ' value shown in the Series 1 table does demonstrate significant differences between experimental conditions, attributable 


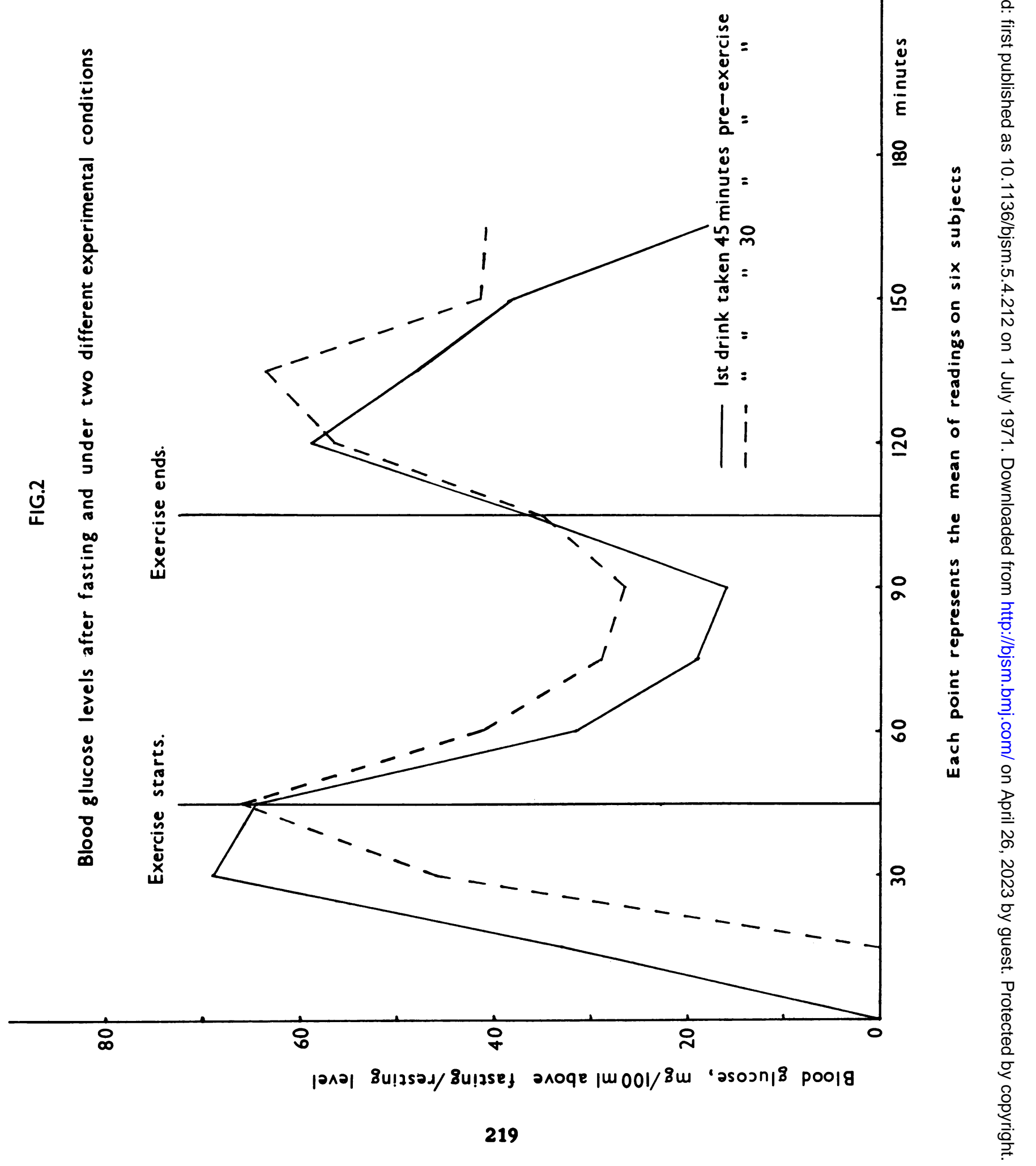




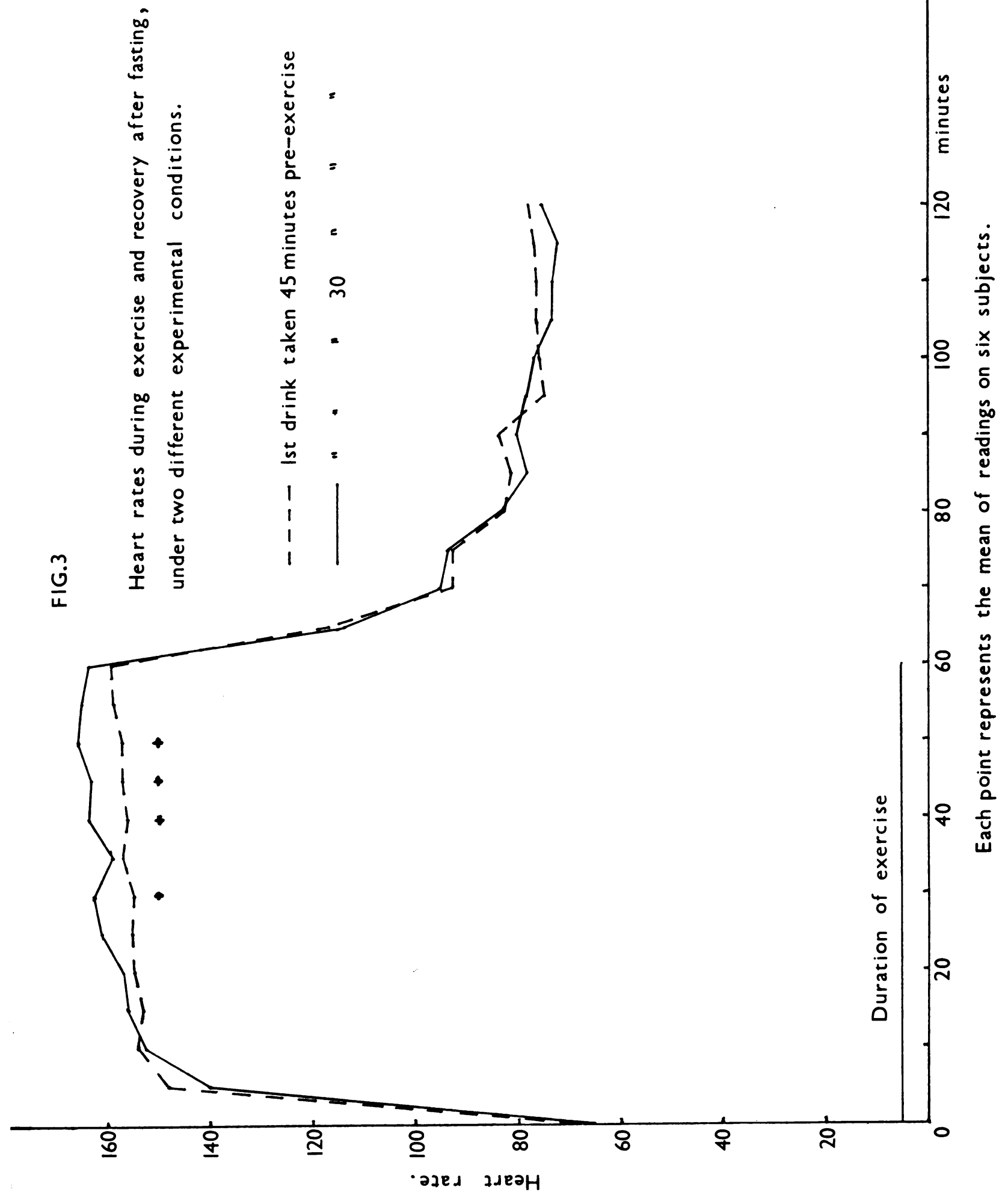


mainly to the 'no-drink exercise' condition. Though the seconday two way analysis fails to show a statistically significant difference in the overall variance between the 'no drink exercise' and the 'exercise-45 minute drink' conditions, the shape of the curves hints that such differences might exist at specific times during exercise. Walsh tests (op.cit.) do, in fact, show that the pre-exercise blood glucose boost is significant, this advantage being maintained during the first quarter of the exercise period. For the remainder of the exercise period there was no real difference between the two. The 15 minute pre-exercise drink appeared to show no advantages, and some disadvantages during exercise by comparison with both the other exercise conditions. During the series it also became apparent that after glucose ingestion there was a significant rise in blood glucose at an hour post-exercise $(\bar{x}=x 40 \mathrm{mg} / 100 \mathrm{ml})$, in both the 15 minutes and the 45 minute pre-exercise drinks. This in itself could be considered of value since many competitors find task performance to suffer during post competitive hypoglycaemia - being especially critical during such tasks as automobile driving. The heart rate during Series 1 tended to reflect the glucose data, the only significant difference being a lower mean heart rate rise during the first 15 minutes of exercise of 13.3 beats (sig.level 0.016 ).

Since Series 1 had shown that subjects differed in their reaction to glucose ingestion, that the timing of the drink was critical, and that pre-exercise and early exercise blood glucose boosts were not necessarily maintained throughout exercise, it was decided in Series 11 to test for the differences between two conditions of glucose ingestion. The first drink of $150 \mathrm{ml}$ was taken at 45 minutes (condition1) or 30 minutes (condition 2) pre-exercise, and subsequent drinks of $50 \mathrm{ml}$ were administered at 30 minute intervals to stimulate competitive feeding techniques. It was hypothesized that a higher blood glucose would be maintained during the whole course of exercise.

The preliminary analysis of variance was performed on twelve time points pre, during and post-exercise. The data are presented graphically in Figures 2 and 3 , and the analysis shows virtually no difference between the two conditions of drink ingestion with regard to the overall variance, though there are the usual significant specific subject interactions. Some specific point by point differences can be discerned by Walsh testing (op.cit.), but the differences in absolute terms are not sufficiently great to give indication of the inherent superiority of one condition over the other.

If, however, the analysis starts from the premise that subjects are highly specific in their reaction to the drink and the conditions under which it is ingested, then the comparisons should not be made between one condition and another, since this merely illustrates the between-subjects difference which, once removed leaves a negligible 'between-conditions' difference. The comparison should more validly be made between a subject's 'best' condition and his 'worst'. 
If the data re regrouped in this way for the six subjects, as shown in Figures 4 and 5 , the two curves are obviously different. The data grouping having been structured, it is valid to apply only certain statistical tests to them; but if the difference between the best and worst performances of subjects is taken as a reflection of the random variation normally obtained in a test-retest situation, then the significance of the observed variation can be tested by factorial analysis of variance. The following are the results of analyzing the blood glucose variance in this way:

\begin{tabular}{l|c|r|c|c|c}
\hline \multicolumn{1}{c|}{ Source } & Sum of Squares & df & Variance Est. & 'F' Ratio & Sig. \\
\hline Subjects & 18897.16 & 5 & 3779.43 & 7.73 & $<0.001$ \\
Condition (best or worst) & 18814.72 & 1 & 18814.72 & 38.53 & $<0.001$ \\
Time (during condition) & 51275.50 & 11 & 4661.40 & 9.64 & $<0.001$ \\
S v C interaction & 1586.95 & 5 & 317.39 & - & N.S. \\
S v T interaction & 36876.34 & 55 & 670.47 & 1.37 & N.S. \\
C v T interaction & 3654.11 & 11 & 332.29 & - & N.S. \\
Residual & 26857.22 & 55 & 488.31 & & \\
\hline Total & 157962.00 & 143 & & & \\
\hline
\end{tabular}




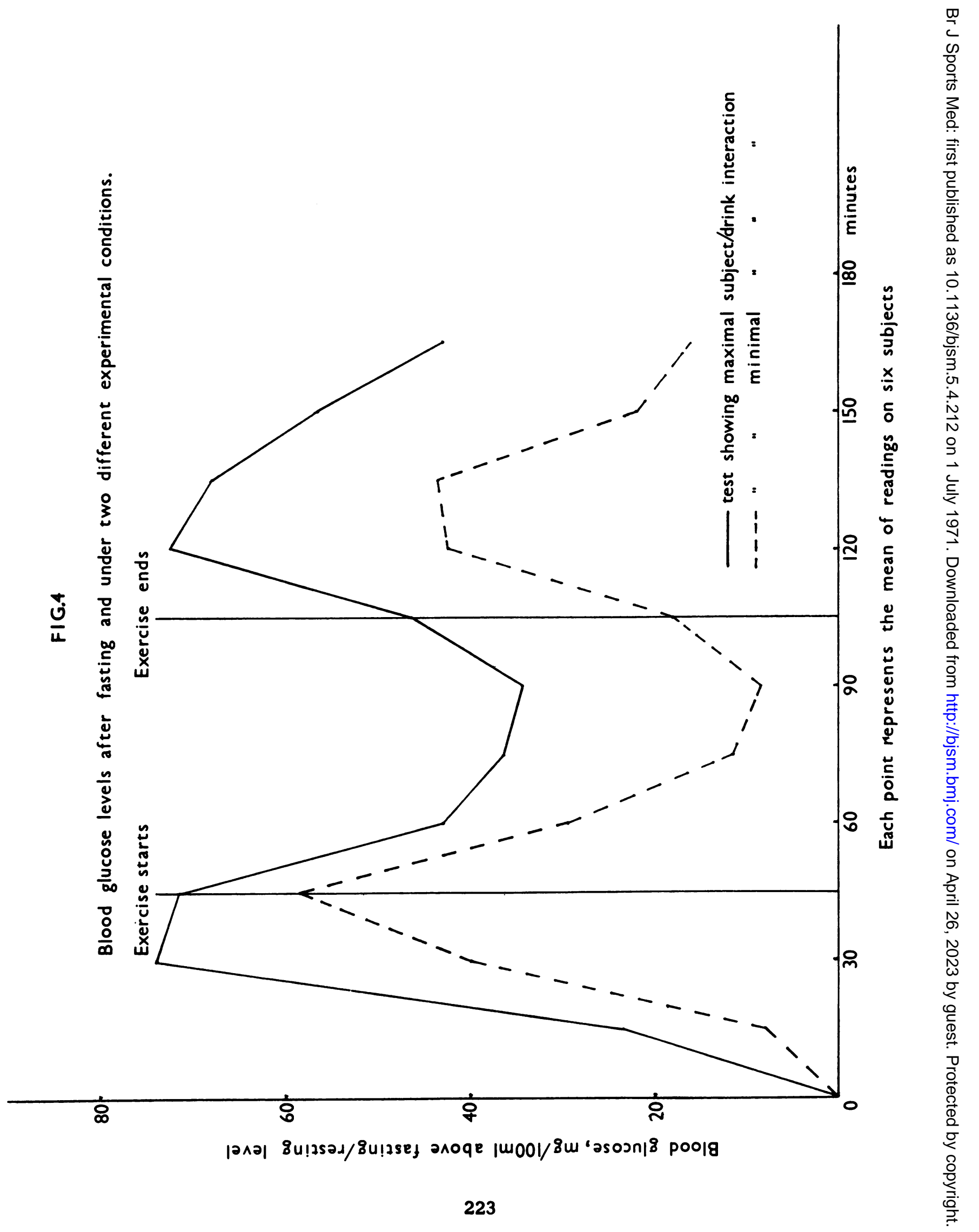


The factorial analysis of variance of the heart rate data, treating the exercise and the rest periocis as two separate phases, with twelve times of recording during each phase, is as follows:

\begin{tabular}{|c|c|c|c|c|c|}
\hline Source & $\begin{array}{l}\text { Sum of } \\
\text { Squares }\end{array}$ & df & Variance Est. & 'F' Ratio & Sig. \\
\hline$S=$ Subjects & 20436.82 & 5 & 4087.34 & 92.07 & $<0.001$ \\
\hline $\mathrm{P}=$ Phase (exercise or rest) & 391907.54 & 1 & 391907.54 & 8828.73 & $<0.001$ \\
\hline$C=$ Condition (best or worst) & 2628.10 & 1 & 2628.10 & 59.2 & $<0.001$ \\
\hline $\mathrm{T}=$ Time (during phases) & 3239.80 & 11 & 294.52 & 6.73 & $<0.001$ \\
\hline $\mathrm{S}$ v $\mathrm{P}$ interaction & 9711.06 & 5 & 1942.21 & 43.75 & $<0.001$ \\
\hline S v C interaction & 1505.24 & 5 & 3301.02 & 6.78 & $<0.001$ \\
\hline $\mathrm{S} \vee \mathrm{T}$ interaction & 1713.68 & 55 & 31.15 & - & N.S. \\
\hline$P$ v C interaction & 24.52 & 1 & 24.52 & - & N.S. \\
\hline $\mathrm{P} \mathbf{v} \mathrm{T}$ interaction & 18565.16 & 11 & 1687.74 & 38.03 & $<0.001$ \\
\hline $\mathrm{C} v \mathrm{~T}$ interaction & 543.60 & 11 & 49.41 & 1.11 & N.S. \\
\hline S v P v C interaction & 2149.85 & 5 & 429.97 & 9.68 & $<0.001$ \\
\hline S v P v T interaction & 2714.24 & 55 & 49.34 & 1.11 & N.S. \\
\hline $\mathrm{S} v \mathrm{C}$ v T interaction & 2052.06 & 55 & $27 \cdot 31$ & - & N.S. \\
\hline $\mathrm{P} v \mathrm{C} v \mathrm{~T}$ interaction & 461.58 & 11 & 41.96 & - & N.S. \\
\hline Residual & 2486.05 & 56 & 44.39 & & \\
\hline Total & 460139.30 & 287 & & & \\
\hline
\end{tabular}

It can now be seen that highly significant differences exist for individual subjects, both in terms of blood glucose and heart rates, between conditions of glucose drink ingestion before extended exercise. These differences apply both during and post-exercise, and indicate that the higher blood glucose which ensues from the preferred ingestion condition is accompanied by greater efficiency during exercise and recovery, manifested by lower heart rates for similar work loads. 





1. Ingestion of a proprietary glucose drink significantly raises blood glucose levels during and after extended sub-maximal exercise.

2. Subjects differ significantly in their heart rate and blood glucose responses to glucose drink ingestion, during and after extended sub-maximal exercise.

3. Significant differences exist between the effects of different glucose drink ingestion times upon subsequent performance of sub-maximal extended exercise - these differences being highly specific to each subject.

It is the intention of the author to undertake further tests, to study the effects of glucose ingestion upon performance during extended, intermittent, high intensity activity.

Acknowledgement is made to Beecham Products (Research and Development Department), for assistance in chemical analysis of blood samples, and for the provision of quantities of CALSAL, the athletes ' glucose drink used in the tests and reported in the Bulletin of Beecham Products 1970.

References:

Ahlborg, B. 'Blood Glucose during Prolonged Physical Exercise in Main', Foisvarsmedicin 3, 1967, 3-13.

Ames Co. Ltd. 'General Production Informations Clinistic'.

Astrand, p-O. and I. Rhyming, 'A Nomogram for Calculation of Aerobic Capacity (Physical Fitness) from pulse rate during sub-maximal work', J. appl. Physiol. 8, 1954, 218-221.

Beckman Inst. Ltd. 'D2 Oxygen Analyser - Operating Instructions', Bull.202C. Boge, O. 'Der Bludzueker wahrend und nach korperlicker Arbeit', Skand. Arch. Physiol. Suppl. 10, 1936, 1.48.

Bull, 'Liquid Glucose in Therapeutics, Nutrition and Research', Bull. Beecham Foods Nut. Res. Dept., Brentford, 1966.

Calsal, 'Athletes' glucose drink', Bull. Beecham Products, Brentford, 1970.

Carlson, L.A., R.J.Havel, L. Ekelund, and A. Holmgren, 'Effect of nicotinic acid on the turnover rate and oxidation of the free fatty acids of plasma in man during exercise', Metabolism, 12, 1963, 837.

Christensen, E.H. and O. Hansen, "Hypoglykamie, Arbeitsfahigkeit und Ermudung' Skand. Arch. Physiol. 81,1939, 172-179.

Consolazio, C.F., L.O. Matoush, H.L. Johnson, H.J.Krzywicki, T.A.Daws and G.J. Issaac, 'Effects of High Carbohydrate Diets on Performance and Clinical Symptomatology after rapid ascent to high altitude', Fed. Proc. 28, 1969, 937-943. 
Down, M. 'Dietary Considerations for Endurance Events', Brit. J. of Sports Med. IV , 1, 1968, 5-26.

Drew, C.D.M. and D.T.D. Hughes, 'Characteristics of the Vitalograph Spirometer' Thorax, 24,6, 1969, 703-706.

Friedberg, S.J., W.R.Harlan, D.L. Trout and E.H. Estes, 'The Effect of exercise on the concentration and turnover of plasma nonesterified fatty acids', J. clin. Invest. 39, 1960, 215.

Goldstein, M.S., V. Mullick, B. Huddlestun, and L. Rachmiel, 'Action of Muscular Work on Transfer of Sugars across Cell Barriers: Comparison with Action of Insulin', Am. J. Physiol. 173, 1953,212-216.

Havel, R.J., A. Naimark, and C.F. Borchgrevink, 'Turnover rate and oxidation of free fatty acids of blood plasma in man during exercise: $S_{t}$ udies during continuous infusion of palmitate - I - C 14, J. clin. Invest. 42, 1963,1054.

Heron E.T.' 'Instructions for taking blood pressure', Accoson Bull., London. Issekutz, B., N.C. Berkhead, and K. Rodahl, 'Fat and carbohydrate in the expenditure of energy during exercise'. J. Nutr. 79, 1963, 109.

Nirkey, G., A. Dawson and V. Marks, 'Manual and Autoanalyzer methods measuring blood glucose using guaiacum and glucose oxidas', Proc.Ass. of clin. Biochem. 5, 1968.2.

Pruett, E.D.R. 'Glucose and insulin during prolonged work stress in men living on different diets' ', J. appl. Physiol. 28, 2, 1970, 199-208.

Reinheimer, W., P.C.Davidson and M.J.Albrink, 'Effect of moderate exercise on plasma, glucose, insulin and free fatty acids during oral glucose tolerance tests', Jnl. Lab. clin. Med. 71, Mar. 1968, 429-437.

Robson H.E. 'Some practical considerations of physique assessment', Brit. J. of Sports Med. 1V, 4, 1970, 300-302.

Rodahl, L., H.I. Miller and B. Issekutz Jr., 'Plasma Free Fatty Acids in Exercise'. J. appl. Physiol. 19, 1964, 489-492.

Saltin, B., and L. Hermansen, 'Glycogen stores and prolonged severe exercise', Symp. Nutr. Found. V, 1967.

Sanders, C.A., G.C. Levinson, W.H. Abelmann and N. Frienkel, 'Effect of exercise on the peripheral utilisation of glucose in man', New Engl. J. Med. $271,1964,220$.

Satterthwaite F.E. 'An approximate distribution of estimates of variance components' , Biometr, Bull. 2, 1946, 110-114.

Thomas.V. 'Science and Sport', Faber and Faber, London, 1970, 118.

Thomas. V. 'Laboratory testing of an ergonenic acid', Br. J. of Sports Med. $\mathrm{V}, 3,1970,159-60$.

Walsh J.E. 'Applications of some significance tests for the median which are valid under very general conditions'. J. Am. Statist, Ass. 44, 1949, 342.355

Whichelow, M.J. W.J.H. Butterfield, M.E. Abrams, C. Sterky and C.J. Garratt, ' The effect of mild exercise on glucose uptake in human forearm tissues in the fasting state and after oral glucose administration', Metabolism 17, $1968,84-95$. 